1 Laboratory of Tumor Genetics, IST-Genova Largo Rosanna Benzi 10, Genova 16132, Italy

2 Laboratory of Immuno-pharmacology, Istituto Nazionale per la Ricerca sul Cancro (IST-Genova), Largo Rosanna Benzi 10, Genova 16132, Italy

3 Differentiation Therapy Unit, Laboratory of Oncology, Istituto G Gaslini, Largo G Gaslini 5, Genova 16147, Italy

4 These authors contributed equally to this work

* Corresponding author: S Ferrini, Laboratory of Immuno-pharmacology, Istituto Nazionale per la Ricerca sul Cancro, Largo Rosanna Benzi 10, Genova 16132, Italy. Tel: + 39-0105737-372; Fax: + 39-0105737-374;

E-mail: silvano.ferrini@istge.it

1. Tamm I et al. (2001) Lancet Oncol. 2: 33-42

2. Fischer U et al. (2003) Cell Death Differ. 10: 76-100

3. Nunez $G$ et al. (1998) Oncogene 17: 3237-3245

4. Muzio M et al. (1996) Cell 85: 817-827

5. Boldin MP et al. (1996) Cell 85: 803-815

6. LeBlanc HN and Ashkenazi A (2003) Cell Death Differ. 10:66-75

7. Peter ME and Krammer PH (2003) Cell Death Differ. 10: 26-35

8. Eggert A et al. (2001) Cancer Res. 61: 1314-1319

9. Fulda $\mathrm{S}$ et al. (2001) Oncogene 20: 5865-5877
10. Teitz T et al. (2000) Nat. Med. 6: 529-535

11. Annicchiarico-Petruzzelli M (2001) Med. Pediatr. Oncol. 36: 115-117

12. Fulda S and Debatin KM (2002) Oncogene 21: 2295-2308

13. Yang $X$ et al. (2003) Cancer Res. 63: 1122-1129

14. Banelli $B$ et al. (2002) Nat. Med. 8: 1333-1335

15. Ramana CV et al. (2000) Oncogene 19: 2619-2627

16. Muhlethaler-Mottet A et al. (1997) EMBO J. 16: 2851-2860

17. Storm van's Gravesande K et al. (2002) J. Immunol. 168: 4488-4494

18. Tanaka N et al. (1993) Mol. Cell. Biol. 13: 4531-4538

19. Decker T et al. (1997) J. Interferon Cytokine Res. 17: 121-134

20. Liedtke $C$ et al. (2003) J. Biol. Chem. 278: 27593-27604

21. Refaeli $Y$ et al. (2002) J. Exp. Med. 196: 999-1005

22. Fernandes-Alnemri T et al. (1996) Proc. Natl. Acad. Sci. USA 93: 7464-7469

23. Himeji $D$ et al. (2002) Blood 99: 4070-4078

24. Xi H and Blanck G (2003) Mol. Immunol. 39: 677-684

25. Blanco JC et al. (2000) J. Exp. Med. 191: 2131-2144

26. Falvo JV et al. (1995) Cell 83: 1101-1111

27. Thanos D and Maniatis T (1995) Cell 83: 1091-1100

28. Muhlethaler-Mottet A et al. (1998) Immunity 8: 157-166

29. Gongora $C$ et al. (2000) Nucleic Acids Res. 28: 2333-2341

30. Boyd KE et al. (1998) Proc. Natl. Acad. Sci. USA 95: 13887-13892

\title{
Corrigendum
}

\section{Subcellular localisation of Cdc25A determines cell fate}

\author{
C Leisser, G Rosenberger, S Maler, G Fuhrmann, M Grusch, \\ S Strasser, S Huettenbrenner, S Fassl, D Polgar, S Krieger, \\ C Cerni, R Hofer-Warbinek, R deMartin and G Krupitza \\ Cell Death and Differentiation (2004) 11, 134. doi:10.1038/ \\ sj.cdd. 4401370
}

Correction to: Cell Death and Differentiation advanced online publication 5 September 2003; doi:10.1038/ sj.cdd. 4401318

Since the advanced online publication, the authors have identified an error. The spelling of $R$ deMartin is incorrect, the correct spelling should be: $\mathrm{R}$ de Martin. 